Abbreviated Key Title: Sch J Med Case Rep

ISSN 2347-9507 (Print) | ISSN 2347-6559 (Online)

Journal homepage: https://saspublishers.com/sjmcr/

\title{
Tamponade Mimicking a Surgical Abdomen and Revealing HIV Infection
}

Yasmine Chafai*, Mohammed Amine Raouah, Hafssa Rouam, Mohamed Jamili, Mustapha El Hattaoui

Cardiology Department of Mohamed VI University Hospital, Marrakech Morocco

DOI: $10.36347 /$ sjmcr.2020.v08i03.013

| Received: 17.02.2020 | Accepted: 25.02.2020 | Published: 11.03.2020

*Corresponding author: Yasmine Chafai

Abstract

Case Report

Low pressure tamponade is a rare entity and difficult to diagnose. We report in our observation concerning this pathology, a patient initially admitted for a surgical emergency, and in whom the initial assessment finds a field of immunosuppression, without germ isolated in the bacteriological examination of the pericardial fluid. This observation underlines the difficulty of diagnosing this form of tamponade as well as the interest of using transthoracic ultrasound as a first-line examination to guide the diagnosis in emergency situations.

Keywords: tamponade, transthoracic ultrasound, immunosuppression.

Copyright @ 2020: This is an open-access article distributed under the terms of the Creative Commons Attribution license which permits unrestricted use, distribution, and reproduction in any medium for non-commercial use (NonCommercial, or CC-BY-NC) provided the original author and source are credited.

\section{INTRODUCTION}

Tamponade is a serious, life-threatening shortterm clinical entity, the diagnosis of which is easy compared to a typical presentation with the classic Beck triad. However, the signs are rarely complete and lead to confusion with other pathologies which can greatly complicate the diagnosis and delay treatment.

\section{Observation}

A.L is a 41-year-old patient, chronic active smoking, and heavy cannabis user, consultant to a general practitioner in a generalized abdominal pain table associated with food and bilious vomiting in a context of fever and deterioration general condition made of asthenia and weight loss estimated at 5 kilograms, evolving a week before. The initial examination noted a conscious patient, hypotensive at $85 / 52 \mathrm{mmHg}$, a heart rate at $82 \mathrm{bpm}$, muffled heart sounds, an epigastric defense and right hypochondrium and a turgor of the jugular veins, patient having benefited from a vascular filling. The admission assessment showed a leukocytosis at 16420 elements / $\mathrm{mm} 3$, a CRP at $174 \mathrm{mg} / \mathrm{L}$, hepatic cytolysis. Then sent to the emergency room for additional treatment in the surgical environment, upon admission an abdominal ultrasound was done demonstrating a low abundance ascites without other abnormalities, an ECG which shows an electrical alternation and a PQ offset, the chest radiography as to it demonstrates cardiomegaly with an ICT at 0.72. During the performance of his exams the patient presents hemodynamic instability made of hypotension, profuse sweating and coldness of the extremities, a transthoracic echocardiography made in emergency objective a circumferential pericardial effusion of great abundance, the drainage having brought back $1800 \mathrm{cc}$ of hematic fluid. Anti bacillary therapy was started on a host of arguments, without bacteriological evidence, the study of pericardial fluid found no germs. In addition, an HIV serology made before the concept of risky sexual intercourse, positive income, the rest of the results were negative.

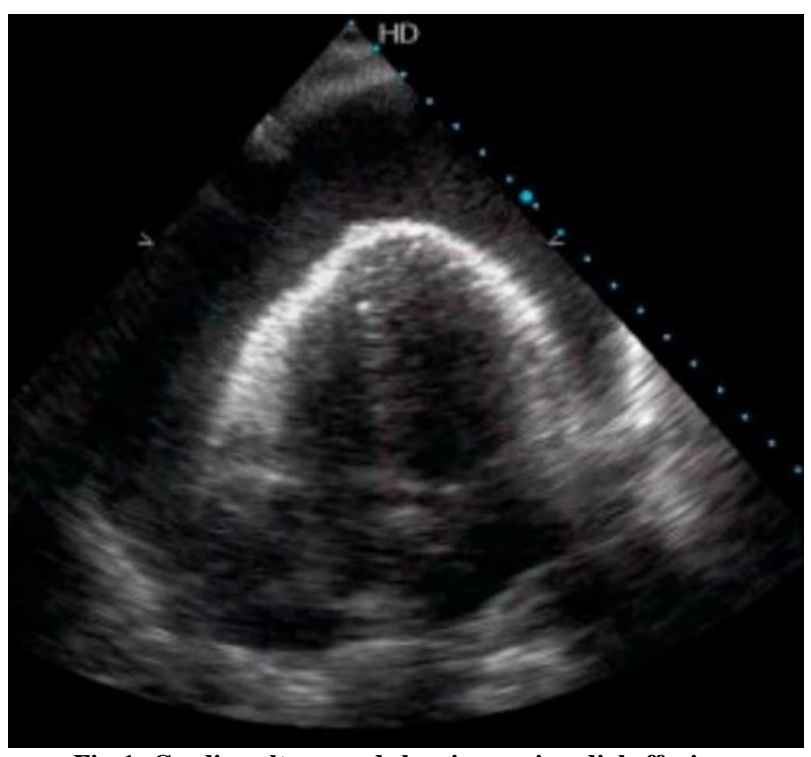

Fig-1: Cardiac ultrasound showing pericardial effusion 


\section{DISCUSSION}

Cardiac tamponade is an absolute medicosurgical emergency involving the patient's vital prognosis in the short term, it is defined as a compression of the heart chambers by a pericardial effusion which can be acute or subacute secondarily to the more or less rapid and more accumulation or less of intrapericardial fluid. The increase in intrapericardial pressures is responsible for the reduction in diastolic filling and the volume of the right ventricular flushing chamber [1]. The systemic consequences are an increase in venous pressures. There are therefore clinical signs of right heart failure (dilation of the jugular veins, hepato jugular reflux, edema of the lower limbs...) [2]. Beck's classic triad, paradoxical pulse, collapse and signs of right heart failure, is rarely present. The other signs are just as infrequent or nonspecific: microvoltage, alternating QRS, chest pain, muffled heart sounds [3]. It should be noted that $20 \%$ of the buffers are said to be "low pressure". They are generally characterized on a pathophysiological level by the recording of low intrapericardial pressures in a context of hypovolemia (low right atrial pressures also). Their clinical diagnosis is sometimes difficult, due to the absence of pathognomonic signs such as jugular turgor or the existence of a paradoxical pulse. The first description was made by Antman et al., in 1979 on an elderly hypovolemic patient with tuberculous pericarditis [4]. In another series, low pressure tamponade is essentially characterized by a lower incidence of paradoxical pulse (only $7 \%$ of cases vs $50 \%$ in the case of a complete clinical picture), jugular turgor (22\% vs $55 \%$ in the case of a clinical picture) full clinic). The main symptom remains dyspnea (48\% of cases). However, $31 \%$ of patients remain asymptomatic in this series [5]. In our case, the initial signs are confusing and not specific to tamponade, this table is typical of tamponade at low pressure [6], encountered in hypovolemic patients and are particularly misleading [7]. The diagnosis is essentially based on transthoracic ultrasound, which finds several signs resulting from compression and changes in pressure gradients: the classic aspect of swinging hearth, a diastolic collapse of the right atrium, a proto- and mesodiastolic collapse of the ventricle right and sometimes a diastolic collapse of the left ventricle [8]. Infectious tamponade essentially concerns, like our patient, fragile areas such as immunocompromised people.

\section{CONCLUSION}

Our case highlights two important aspects of pericardial pathology, namely the importance of echocardiography as a simple diagnostic tool, mainly in atypical clinical pictures related to low pressure tamponade, and other apart from the revelation of an underlying area of immunosuppression hitherto unknown.

\section{REFERENCES}

1. Spodick DH. Acute cardiac tamponade. New England Journal of Medicine. 2003 Aug 14;349(7):684-90.

2. Little WC, Freeman GL. Pericardial disease. Circulation. 2006 Mar 28;113(12):1622-32.

3. Maisch B, Seferović PM, Ristić AD, Erbel R, Rienmüller R, Adler Y, Tomkowski WZ, Thiene G, Yacoub MH, Priori SG, Alonso Garcia MA. Guidelines on the diagnosis and management of pericardial diseases executive summary: the Task Force on the Diagnosis and Management of Pericardial Diseases of the European Society of Cardiology. European heart journal. 2004 Apr 1;25(7):587-610.

4. Antman EM, Cargill V, Grossman W. Lowpressure cardiac tamponade. Annals of internal medicine. 1979 Sep 1;91(3):403-6.

5. Permanyer-Miralda G, Soler-Soler J, SagristàSauleda J, Angel J, Sambola A, Alguersuari J. Low-Pressure Cardiac Tamponade: Clinical and Hemodynamic Profile. Circulation, 2006; 114: 945-52.

6. Sagrista' -Sauleda J, Angel J, Sambola A, Permanyer-Miralda G. Hemodynamic effects of volume expansion in patients with cardiac tamponade. Circulation, 2008; 117:1545-1549.

7. Sagrista-Sauleda J, Angel J, Sambola A, Alguersuari J, Permanyer-Miralda G, Soler-Soler J. Low-pressure cardiac tamponade: clinical and hemodynamic profile. Circulation, 2006; 114:94552.

8. Lardoux H, Vayre F, Pezzano M, Dubourg O. Tamponnades. In: Vignon P, Goarin JP, editors. E' chocardiographie Doppler en re'animation, anesthe' sie et me'decine d'urgence. Paris: Elsevier; 2002, 257-72. 